\title{
Story of Management of a Challenging Case of a Fibrotic Uterine Cavity
}

\author{
Nidhi Jain ${ }^{1}$, Hena Kausar ${ }^{2}$, Rahul Manchanda ${ }^{3}$, Sravani Chithra ${ }^{4}$, Anshika Lekhi ${ }^{5}$
}

\begin{abstract}
Aim: Our aim is to highlight the emerging trends of management of a moderate-to-severe degree of Asherman's syndrome/fibrotic uterine cavity in the form of either relook hysteroscopic surgery or postoperative hormonal therapy.

Background: Asherman's syndrome also known as Fritsch syndrome or Fritsch-Asherman syndrome is a condition where iatrogenic intrauterine adhesions (IUA) develop and it occurs most commonly following dilatation and curettage or pelvic infections, e.g., endometrial tuberculosis. Diagnosis is based on the history and a high index of suspicion followed by confirmation by saline infusion sonography (SIS) or hysterosalpingography (HSG). Hysteroscopy is the gold standard for both diagnosis and treatment of Asherman's syndrome. This case highlights the importance of hysteroscopic management of a known case of Asherman's syndrome/IUA and also highlights how important are relook hysteroscopic surgeries and their interval from primary surgery and gradually decreasing the dose of postoperative hormonal therapy to cure the same and to improve the clinical outcome.

Case description: We present a case where a patient underwent curettage after retained products leading to fibrosis of the uterine cavity. Multiple surgeries abroad were unsuccessful to correct the problem. Then patient came to our institute where hysteroscopic adhesiolysis and lateral wall metroplasty along with laparoscopic adhesiolysis and right-sided ovarian cystectomy followed by intrauterine contraceptive device (IUCD) insertion, i.e., multiload without copper was done followed by two more relook hysteroscopic procedures leading to reformation of a normal uterine cavity. The authors discuss the stepwise management of a known case of Asherman's syndrome through this successful and challenging case.
\end{abstract}

Conclusion: IUA develop most commonly after vigorous curettage or endometrial tuberculosis. Diagnosis is based on the history and a high index of suspicion and confirmation by SIS and HSG. The hysteroscopic management of IUA is a safe and effective method. It is a surgical pearl for both diagnostic and therapeutic purposes. Sequential estrogen and progesterone therapy and a splint are found to be helpful, but further studies are needed to assess their efficacy. Relook hysteroscopy acts as an adjunctive method to improve the outcome. We emphasize on relook hysteroscopy and its interval from the primary surgery which is usually after next menses when the patient resumes menses as it helps to get a better and long-term clinical outcome.

Clinical significance: Hysteroscopy acts as both a diagnostic and therapeutic tool for the management of fibrotic uterine cavity. Relook hysteroscopic surgery is useful to manage a moderate-to-severe degree of fibrotic uterine cavity along with insertion of IUCD without copper to prevent further adhesions. Gradually decreasing the dose of hormonal therapy (estrogen plus progesterone) helps to regenerate the endometrium and to resume normal menses.

Keywords: Asherman's syndrome, Hysteroscopy, Intrauterine adhesions, Metroplasty.

Journal of South Asian Federation of Obstetrics and Gynaecology (2020): 10.5005/jp-journals-10006-1829

\section{BACKGROUND}

Asherman's syndrome also known as Fritsch-Asherman syndrome is a condition where intrauterine adhesions (IUA) develop most commonly following vigorous curettage of a gravid uterus following infection, e.g., endometrial tuberculosis, myomectomy or removal of septa. This occurs due to the denudation of the basal layer which acts as a regenerative reservoir of the endometrium.

The syndrome is expressed by infertility (43\%) and menstrual disorders (62\%). ${ }^{1}$ Clinically, these adhesions result in sterility, abortion, hypomenorrhea, amenorrhea, etc. Diagnosis is based on the history and a high index of suspicion followed by confirmation by saline infusion sonography (SIS) or hysterosalpingography (HSG). Hysteroscopy is the gold standard for both diagnosis and treatment of Asherman's syndrome. Hysteroscopic adhesiolysis followed by insertion of intrauterine device (IUD)/balloon stent inside the uterus combined with sequential estrogen plus progesterone therapy helps to cure the disease and to resume menses. It also helps to conceive in the future if the problem is addressed precisely and managed properly.
${ }^{1}$ Department of Gynaecology Endoscopy, Maharaja Agrasen Medical College, Hisar, Haryana, India

${ }^{2-5}$ Department of Gynaecology Endoscopy, Manchandas Endoscopic Centre, New Delhi, India

Corresponding Author: Hena Kausar, Department of Gynaecology Endoscopy, Manchandas Endoscopic Centre, New Delhi, India, Phone: +919810017651, e-mail: drsravanichithra@yahoo.com

How to cite this article: Jain N, Kausar H, Manchanda R, et al. Story of Management of a Challenging Case of a Fibrotic Uterine Cavity. J South Asian Feder Obst Gynae 2020;12(6):432-435.

Source of support: Nil

Conflict of interest: None

This case highlights the importance of hysteroscopic management of a known case of Asherman's syndrome/IUA and also highlights how important are relook hysteroscopic surgeries and gradually decreasing the dose of postoperative hormonal therapy to cure the same and improve the outcome.

( ) Jaypee Brothers Medical Publishers. 2020 Open Access This article is distributed under the terms of the Creative Commons Attribution 4.0 International License (https://creativecommons.org/licenses/by-nc/4.0/), which permits unrestricted use, distribution, and non-commercial reproduction in any medium, provided you give appropriate credit to the original author(s) and the source, provide a link to the Creative Commons license, and indicate if changes were made. The Creative Commons Public Domain Dedication waiver (http://creativecommons.org/publicdomain/zero/1.0/) applies to the data made available in this article, unless otherwise stated. 


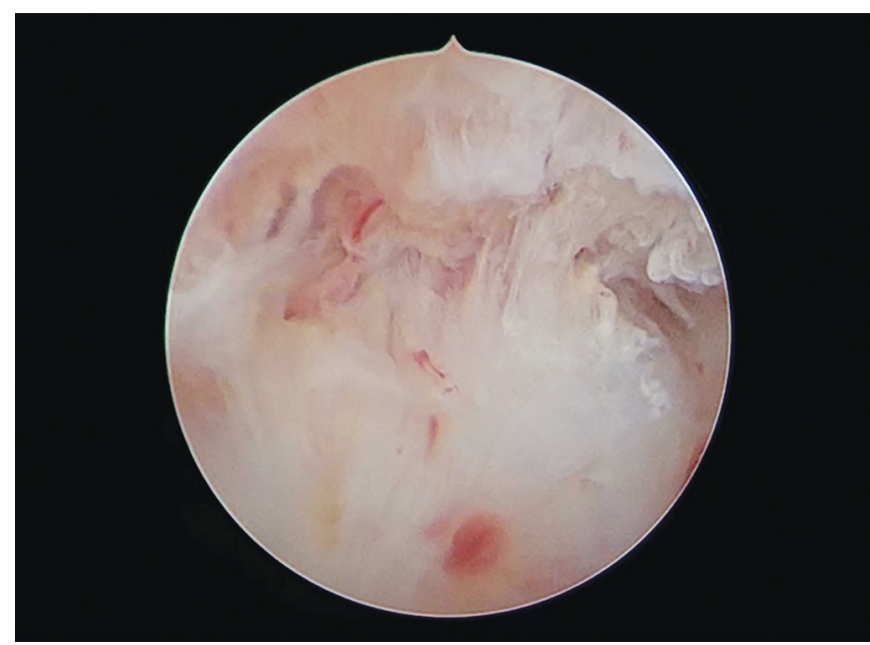

Fig. 1: Severe degree of fibrotic uterine cavity (during primary hysteroscopic surgery before adhesiolysis)

\section{Case Description}

We present a case of Mrs. X, 35 years old, P2L2A1 with a history of amenorrhea for the last 2 years with a preceding history of abortion followed by vigorous curettage. She came to us as a diagnosed case of severe Asherman's syndrome and was a known case of hypothyroidism on Thyronorm $125 \mathrm{mcg} \times 12$ years. USG (ultrasonography) was not very informative except for showing a right adnexal mass of about $55.33 \times 45.45 \mathrm{~mm}$ with clear fluid. HSG showed bilateral tubal blockades with a significant filling defect in the uterus. Laboratory evaluation of serum pregnancy test, complete blood count, follicle-stimulating hormone, thyroid-stimulating hormone, and prolactin were normal. Her general physical examination was normal. The patient underwent laparoscopic and hysteroscopic surgeries abroad without any improvement in her clinical status. The patient was planned for a diagnostic and operative hysteroscopic and laparoscopic surgery. Hysteroscopic findings showed the vagina to be normal, endocervical canal adhesions present, uterine cavity obliterated with dense adhesions greater than two-thirds of the tubular cavity, bilateral ostia not visualized (Fig. 1). Hysteroscopic adhesiolysis with lateral wall metroplasty with reconstruction of the uterine cavity with multiload insertion without copper was done. Laparoscopic findings showed adhesions between the ovary and the lateral pelvic wall. Laparoscopic adhesiolysis with right ovarian cystectomy with chromopertubation was also done. Bilateral free spillage was seen. The patient withstood the procedure well and was discharged on the second day. The patient was given a high dose of conjugated estrogen (oral conjugated equine estrogen [CEE] $0.625 \mathrm{mg}-2$ tab qid) for 21 days followed by progesterone (oral medroxyprogesterone acetate [MPA] $10 \mathrm{mg}-1 \mathrm{bd}$ ) for the next 7 days. The patient resumed menses with a normal flow and she used 3 pads/day for the first 3 days. The duration of flow was around 6-7 days. The patient was planned for the first relook surgery after her next menses, i.e., after about 4 weeks. First relook hysteroscopy with adhesiolysis with multiload insertion without copper (previous intrauterine contraceptive device [IUCD] removed) was done and then the patient was discharged on a day-care basis. Relook hysteroscopic findings showed the vagina to be normal but a blue thread of multiload seen, cervix healthy,

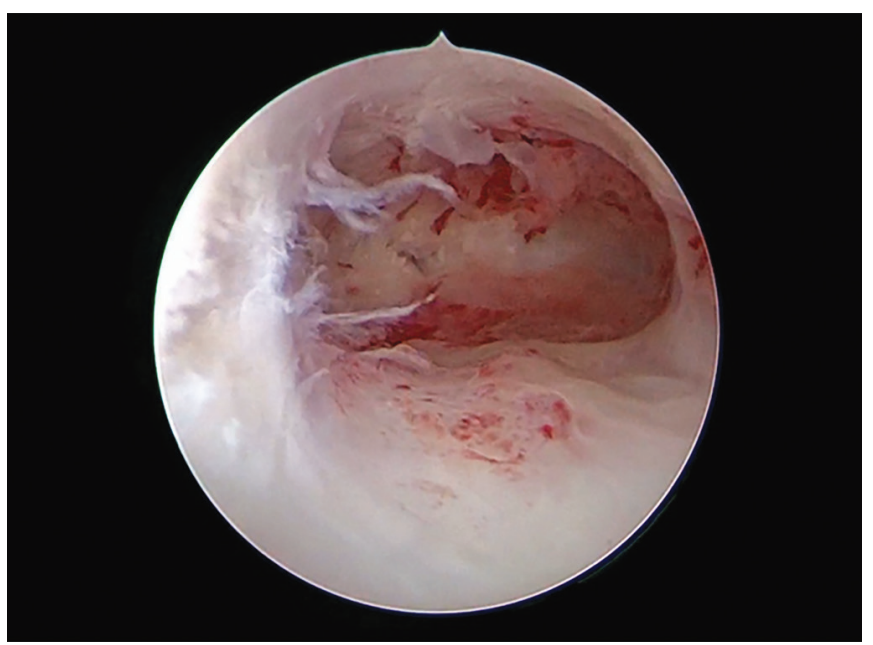

Fig. 2: After second relook hysteroscopic surgery (almost normal uterine cavity after adhesiolysis)

IUD without copper seen and removed, uterine cavity appreciable much better than before with new fresh endometrial growth. Adhesions were present on the right lateral wall and fundus which were cut and normalized. IUCD without copper was placed inside the uterine cavity. Postoperatively, she was given sequential estrogen (oral CEE $0.625 \mathrm{mg}-2 \mathrm{tab}$ bd) plus progesterone therapy (oral MPA $10 \mathrm{mg}-1 \mathrm{bd}$ )—for her next cycle. The patient had her menses after about 4 weeks and second relook surgery was again planned after her next menses. Second relook hysteroscopy with IUCD removal was done. Findings showed IUCD thread visibleremoved, normal endocervical canal, normal uterine cavity, and a proliferative endometrium (Fig. 2). The patient was discharged on a day-care basis in a stable condition. Again, the patient was given sequential estrogen (oral CEE $0.625 \mathrm{mg}-1 \mathrm{bd}$ ) plus progesterone therapy (oral MPA $10 \mathrm{mg}-1 \mathrm{bd}$ ) for her next cycle. The patient was followed for the next 6 months. During this period, she had normal menses as described before without any complaint. She is doing fine till now.

\section{Discussion}

Asherman's syndrome is a well-known cause of abnormal menstrual pattern ranging from normal menses to hypomenorrhea or amenorrhea. Clinical manifestations depend on the severity of the disease. The sine qua non for the development of intrauterine adhesions is an endometrial trauma either by direct physical interaction primarily curettage or by infection. Tam et al. randomized 82 patients with spontaneous incomplete abortion to observation, medical or surgical management. ${ }^{2}$ Outcomes were similar, and hysteroscopy 6 months later detected IUA only in the postcurettage group. Increasingly, cases are associated with abdominal/hysteroscopic myomectomy, removal of septa, and any other intrauterine surgery. Taskin et al. detected IUA following the hysteroscopic removal of a single myoma in $31.3 \%$ of cases. ${ }^{3}$ This rose to $45.5 \%$ if multiple myomectomy was done. IUA followed hysteroscopic resection of the septum in $6.7 \%$ of cases. The true incidence is unknown. Hypoestrogenism is associated with extensive intrauterine scar formation. ${ }^{4}$ Pathological finding includes development of fibrous connective tissue bands with or without glandular tissue ranging from flimsy to dense. 
Table 1: Protocol of postoperative hormonal therapy in this patient

\begin{tabular}{|c|c|c|}
\hline Hysteroscopic surgeries & Drugs/medicine & Duration \\
\hline \multirow[t]{2}{*}{$\begin{array}{l}\text { Primary hysteroscopic } \\
\text { surgery }\end{array}$} & $\begin{array}{l}\text { Oral conjugated equine } \\
\text { estrogen (CEE) ( } 0.625 \mathrm{mg}) \text { - } \\
2 \text { tab qid }\end{array}$ & $\begin{array}{l}\text { For initial } \\
21 \text { days }\end{array}$ \\
\hline & $\begin{array}{l}\text { Oral medroxyprogesterone } \\
\text { acetate (MPA) (10 mg)-1 tab } \\
\text { bd }\end{array}$ & $\begin{array}{l}\text { For the } \\
\text { next } 7 \text { days }\end{array}$ \\
\hline \multirow[t]{2}{*}{$\begin{array}{l}\text { First relook hystero- } \\
\text { scopic surgery }\end{array}$} & Oral CEE $(0.625 \mathrm{mg})-2 \mathrm{tab} \mathrm{bd}$ & $\begin{array}{l}\text { For initial } \\
21 \text { days }\end{array}$ \\
\hline & Oral MPA (10 mg)-1 tab bd & $\begin{array}{l}\text { For the } \\
\text { next } 7 \text { days }\end{array}$ \\
\hline \multirow[t]{2}{*}{$\begin{array}{l}\text { Second relook hyster- } \\
\text { oscopic surgery }\end{array}$} & Oral CEE $(0.625 \mathrm{mg})-1 \mathrm{tab} \mathrm{bd}$ & $\begin{array}{l}\text { For initial } \\
21 \text { days }\end{array}$ \\
\hline & Oral MPA (10 mg)-1 tab bd & $\begin{array}{l}\text { For the } \\
\text { next } 7 \text { days }\end{array}$ \\
\hline
\end{tabular}

Diagnosis is primarily based on the history and a high index of suspicion. Confirmation is done by SIS and HSG. Hysteroscopy was mentioned by Asherman in 1948 and figures prominently in review articles by Schenker and March and remains an important method of diagnosis and treatment. ${ }^{1,5,6}$ We emphasize the importance of relook hysteroscopic surgeries for the management of moderateto-severe IUA. The type of IUCD is not specified rather it should be of large surface area and inert variety.

The lack of universally accepted classification system makes the comparison of treatment methods more difficult. Treatment of Asherman's syndrome has evolved over years since its initial description. Modern treatment has focused on using hysteroscopy as the main modality. Our patient underwent successful treatment of IUA through primary hysteroscopic and relook hysteroscopic surgeries. IUCD helped in preventing the reformation of adhesions and adjunctive estrogen plus progesterone therapy helped in regeneration of the endometrium followed by resumption of normal menses (Table 1). Schenker and Margalioth used short estrogen therapy and placement of an IUD following curettage for a missed abortion and reported "most encouraging results" in the prevention of IUA compared with historic controls. ${ }^{7}$ Massouras reported similar findings with only IUD placement. ${ }^{8}$ Numerous estrogen regimens have been promoted but usually are $5.0 \mathrm{mg}$ CEE or its equivalent daily in divided doses for at least 30 days followed by adding MPA or equivalent for 10 days. ${ }^{6}$ Several other methods for reducing the reformation of adhesions have been advocated including the use of amnion around the balloon catheter and the use of spray gel adhesion barrier after electrocautery lysis of adhesions. ${ }^{9,10}$ Prophylactic antibiotics are not proven to be mandatory but given in our case postoperatively.

Very little literature is available about relook hysteroscopic surgeries, its indications, and interval from primary surgery. We assess the uterine cavity by HSG or an in-office hysteroscopy. The latter, performed soon after the initial procedure, permits further adhesiolysis at a time when any reforming scars are thin and filmy and easily lysed. ${ }^{11}$ If HSG or hysteroscopy is normal, a midcycle ultrasound of the endometrium is performed to assess endometrial development. If there is a significant improvement in the uterine architecture and endometrial development but results show persistent scarring, patients are offered another surgery. In a significantly obliterated cavity, multiple procedures may be needed to achieve a satisfactory outcome. Time interval
Table 2: Protocol of relook hysteroscopy in this patient

\begin{tabular}{lll}
\hline Hysteroscopic surgeries & $\begin{array}{l}\text { Obliteration of } \\
\text { uterine cavity }\end{array}$ & Interval/gap \\
\hline $\begin{array}{l}\text { Primary hysteroscopic } \\
\text { surgery }\end{array}$ & $>2 / 3^{\text {rd }}$ obliterated & - \\
$\begin{array}{l}\text { First relook hysteroscopic } \\
\text { surgery }\end{array}$ & $<1 / 3^{\text {rd }}$ obliterated & $\begin{array}{l}\text { After about 4 weeks } \\
\text { of primary surgery } \\
\text { (next menses) }\end{array}$ \\
$\begin{array}{lll}\text { Second relook } \\
\text { hysteroscopic surgeries }\end{array}$ & $\begin{array}{l}\text { Uterine cavity } \\
\text { normal }\end{array}$ & $\begin{array}{l}\text { After about 4 weeks } \\
\text { of first relook surgery } \\
\text { (consecutive next } \\
\text { menses) }\end{array}$ \\
\hline
\end{tabular}

of second-look hysteroscopy of less than one month offers better prognosis in the prevention of adhesion reformation for a moderate-to-severe Asherman's syndrome. ${ }^{12}$ In this study ${ }^{12}$ according to the different timings of hysteroscopic examination, they were divided into three groups: $<1$ month, 1-2 months, and $>2$ months. The rate of hysteroscopic adhesiolysis was evaluated by AFS (American fertility score). The median of decreased AFS score and normal uterine rate was as follows: group A: 78\%, group B: $66.7 \%$, group C: $44.4 \%$. In our case, we planned for first relook and second relook hysteroscopic surgeries after her consecutive menstrual cycles which she resumed after treatment (Table 2). It helped us to get better results with a long-term outcome as she is doing fine till now.

\section{Conclusion}

IUA develop most commonly after vigorous curettage or endometrial tuberculosis. Diagnosis is based on the history and a high index of suspicion and confirmation by SIS and HSG. The hysteroscopic management of IUA is a safe and effective method. It acts as a surgical pearl for both diagnostic and therapeutic purposes. Sequential estrogen and progesterone therapy and a splint appear to be helpful, but further studies are needed to assess their efficacy. Relook hysteroscopy acts as an adjunctive method to improve the outcome. We emphasize on relook hysteroscopic surgery for a moderate-to-severe degree of fibrotic uterine cavity and it should be done after about 4-6 weeks when the patient resumes menses. Relook surgery combined with IUCD and gradually decreasing dose of postoperative hormonal therapy helps to get a better and long-term clinical outcome.

\section{Clinical Significance}

Hysteroscopy acts as both a diagnostic and therapeutic tool for the management of fibrotic uterine cavity. Relook hysteroscopic surgery is useful to manage a moderate-to-severe degree of Asherman's syndrome if needed along with insertion of IUCD without copper to prevent further adhesions. Gradually decreasing the dose of hormonal therapy (estrogen plus progesterone) helps to regenerate the endometrium, resume normal menses, and conceive in the future.

\section{Acknowledgment}

We thank Dr. Rahul Manchanda, Director of Manchanda's Endoscopic Centre to help and guide us throughout the whole process of writing this case report. 


\section{References}

1. Schenker JG. Etiology of and therapeutic approach to synechia uteri. Eur J Obstet Gynecol Reprod Biol 1996;65(1):109-113. DOI: 10.1016/0028-2243(95)02315-j.

2. Tam WH, Lau WC, Cheung LP, et al. Intrauterine adhesions after conservative and surgical management of spontaneous abortion. J Am Assoc Gynecol Laparosc 2002;9(2):182-185. DOI: 10.1016/s10743804(05)60129-6.

3. Taskin O, Sadik S, Onoglu A, et al. Role of endometrial suppression on the frequency of intrauterine adhesions after resectoscopic surgery. J Am Assoc Gynecol Laparosc 2000;7(3):351-354. DOI: 10.1016/s10743804(05)60478-1.

4. Buttram VC Jr, Turati G. Uterine synechiae: variations in severity and some conditions which may be conductive to severe adhesions. Int J Fertil 1977;22(2):98-103. PMID: 20418.

5. Asherman JG. Amenorrhea traumatica (atretica). J Obstet Gynaecol Br Emp 1948;55(1):23-30. DOI: 10.1111/j.1471-0528.1948.tb07045.x.

6. March CM. Intrauterine adhesions. Obstet Gynecol Clin North Am 1995;22(3):491-505. PMID: 8524533.
7. Schenker JG, Margalioth EJ. Intrauterine adhesions: an updated appraisal. Fertil Steril 1982;37(5):593-610. DOI: 10.1016/s00150282(16)46268-0.

8. Massouras HG. Intrauterine adhesions: a syndrome of the past with the use of the Massouras duck's foot No. 2 intrauterine contraceptive device. Am J Obstet Gynecol 1973;116(4):576-578. DOI: 10.1016/00029378(73)90918-6.

9. Amer Ml, Abd-EL-Maeboud KH. Amnion graft following hysteroscopic lysis of intrauterine adhesions. J Obstet Gynecol Res 2006;32(6):559566. DOI: 10.1111/j.1447-0756.2006.00454.x.

10. Abott J, Thomson A, Vancaille T. Spraygel following surgery for Asherman's syndrome may improve pregnancy outcome. J Obstet Gynecol 2004;24(6):710-711. DOI: 10.1080/01443610400008206.

11. Robinson JK, Coliman LM, Isaacson KB. Postoperative adhesiolysis therapy for intrauterine adhesions (Asherman's syndrome). Fertil Steril 2008;90(2):409-414. DOI: 10.1016/j.fertnstert.2007.06.034.

12. Li C, Wei ML, Lin XN, et al. Effects of early intervention of second look office hysteroscopy in the prevention of adhesion reformation in moderate-severe Asherman's syndrome. Zhonghua Yi Xue Za Zhi 2013 Dec 3;93(45):3617-3619. DOI: 10.3760/cma.j.issn.0376-2491.2013.45.014. 